Working Paper 98-72

Business Economics Series 14

October 1998
Departamento de Economía de la Empresa

Universidad Carlos III de Madrid

Calle Madrid, 126

28903 Getafe (Spain)

Fax (341) 624-9608

\title{
LICENSING IN THE PRESENCE OF COMPETING TECHNOLOGIES ${ }^{1}$
}

\author{
Ashish Arora ${ }^{*}$ and Andrea Fosfuri ${ }^{* *}$
}

\begin{abstract}
In technology-based industries, many incumbent firms license their technology to other firms that will potentially compete with them. Such a strategy is difficult to explain within traditional models of licensing. This paper extends the literature on licensing by relaxing the widespread assumption of a "unique" technology holder. We develop a model with many technological trajectories for the production of a differentiated good. We find that competition in the market for technology induces licensing of innovations, and that the number of licenses can be inefficiently large. A strong testable implication of our theory is that the number of licenses per patent holder decreases with the degree of product differentiation.
\end{abstract}

Key Words: Technology licensing, market structure, market for technology.

"Financial support from the TSER project, "A green paper on the chemical industry: from science to product", is gratefully acknowledged. We are indebted to Alfonso Gambardella, with whom we are working on a related project, for ongoing suggestions and discussions. The usual disclaimers apply.

"Carnegie Mellon University, Pittsbutgh, USA.

*"Universidad Carlos III de Madrid, Departamento de Economía de la Empresa, C/ Madrid, 126. 28903 Getafe, Madrid, Spain. Phone: 34-91-624.93.51. E-mail: fosfuri@emp 


\section{Introduction}

Intellectual property rights, particularly patents and copyrights, are increasing in importance in a number of technology-intensive industries (see for instance, Cohen et al., 1996). Although firms typically use patents to hold off would-be competitors, many firms are also licensing their patents and associated technology to others. ${ }^{1}$ There are some wellknown examples of large companies consciously adopting a strategy of licensing for generating revenue. For instance, in semi-conductors, Texas Instrument is reported to have earned royalties of over $\$ 1.8$ billion between 1986 to 1993 through licensing, a figure comparable to Texas Instruments' cumulative net income during this period (Grindley and Teece, 1997). Other firms licensing semi-conductor technology include AT\&T, IBM and SGS-Thompson. Similarly, in chemicals, a number of firms including Dow Chemicals, Exxon, Union Carbide, Nova Chemicals and Phillips Petroleum are actively licensing their metallocene catalyst technology ${ }^{2}$ for producing plastics (Arora and Fosfuri, 1998). The noteworthy feature is that all of the firms mentioned are large and have large market shares in the product markets.

This constitutes something of a challenge to traditional wisdom, which holds that an innovator can best exploit innovations by commercializing them itself (e.g. Teece, 1988). ${ }^{3}$ In this view, licensing is undesirable both because the innovator has to share some of the rents with the licensee, and especially because licensing gives rise to increased competition and, hence, rent dissipation. But then how does one explain the use of licensing by major

\footnotetext{
'Elsewhere, we document the widespread incidence of licensing in the chemical industry (Arora, 1997 and Arora and Fosfuri, 1998). Anand and Khanna (1997) in their study of strategic alliances find that licensing is common in other sectors such as biotechnology and computers as well, accounting for about 20 to $33 \%$ of all alliances, depending on the sector. They also find that licensing has increased in frequency between 1990-1993, the time period that they study. A recent survey, by a consulting firm, of 133 companies in the US, Japan and Western Europe in automotive, engineering, bio-pharmaceuticals and electronics found that $75 \%$ of firms license in technology and nearly $66 \%$ license out their technology. Furthermore, expenditure on licensing in technology are about $12 \%$ of total R\&D budget (IPR Market Benchmark Study, by Business Planning and Research International, 1998, London).

${ }^{2}$ Metallocene catalysts are applied to a wide variety of polymers and provide better properties such as impact strength and toughness, melt characteristics and clarity in films.

${ }^{3}$ In the chemical industry, the question of whether or not licensing is sensible has been a matter of considerable debate by business consultants. For instance, Union Carbide has been criticized for its liberal licensing of its polypropylene/polyethylene Unipol process, with the claim that licensing reduced profitability, both for the industry, and also for Union Carbide itself (Spalding, 1986; Spitz, 1988).
} 
producers $?^{4}$ In this paper we develop a simple model that characterizes the conditions under which producers license their technology. We use the model to explore how licensing decisions are affected by factors such as the nature of demand, the strength of intellectual property rights, and the extent of competition from other technology holders.

As we show in the next section, our key departure from the literature on licensing is the relaxing of the assumption of a 'unique' innovator. With competition among technology holders, licensing can be privately rational, even if the joint profits of the incumbents fall. We formalize this intuition in section 3, where we characterize the conditions under which the equilibrium involves licensing and the effects of the nature of demand and of the intellectual property rights regime. Section 4 examines the socially efficient level of licensing and compares it to the equilibrium level of licensing. The licensing behavior of small versus large producers is analyzed in section 5 . The next section shows that, with multiple licensors, increasing the efficiency of licensing contracts can diminish profitability and the incentives for R\&D. Section 7 brings together our main findings and concludes the paper.

\section{Incentives to licensing with one and many technology holders}

Why do firms license their technology? The typical answer is that they license if they are less efficient (or unable) at exploiting the invention than the potential licensee, or they attempt to establish their technology as a de-facto standard. Both of these motivations are well-known and accordingly, in this paper, we assume that neither applies. Instead, we focus on the role of licensing in rapidly expanding the use of technology. Typically, there are significant firm level adjustment costs or other constraints that restrict how rapidly an innovator can expand output. Thus, a technology holder can turn to licensing as a way of exploiting the technology more aggressively. In our model, these constraints are endogenous as the output of technology holders is constrained by the type of commitment problem that is well-known in Cournot competition. ${ }^{5}$ In turn, this implies that we focus on non-exclusive

\footnotetext{
${ }^{4}$ Note also that network externality type phenomena are not important in the examples, so that licensing is not driven by a desire to establish the technology as a de-facto standard, a motive that is important for some licensing decisions in software and computers.

${ }^{5}$ A firm can more credibly commit itself to an expansion in production when it transfers the output decision to a separate entity (the licensee) rather than when it keeps such decision within the firm's boundaries.
} 
licensing contracts, a common practice in technology licensing. (See for example, Anand and Khanna, 1997).

We focus on the case when there are at least two technology holders in the market. Although the introduction of multiple technology holders might appear to be a small modification with respect to the acquired literature on licensing, it turns out to have profound effects on the predictions of the model and on the set of results one can derive. ${ }^{6}$ Specifically, the presence of competing technologies changes the payoff to the strategy of trying to keep one's technology in-house. Licensing imposes a negative pecuniary externality upon other incumbents, which is not taken into account by the licensor. As a result, if there are two or more incumbent firms that have proprietary technologies that are substitutes for each other, both firms may find it privately profitable to license, although their joint profits may well be higher in the absence of any licensing.

The intuition is easier to grasp with the help of a simple duopoly example. Suppose that two firms have independently developed their own technology suitable to produce a given (final or intermediate) product. What is the payoff of the licensing strategy? We need to consider two effects. The first, the revenue effect, is given by the rents earned by the licensee which will accrue to the patent holder in the form of licensing payments. The second, the rent dissipation effect, is given by the erosion of profits due to another firm competing in the downstream market.

If there is only one incumbent in the market the rent dissipation effect dominates the revenue effect whenever industry profits are maximized by a monopoly (as is typically the case). ${ }^{8}$ Instead, when another incumbent exists the losses due to increased competition are

\footnotetext{
${ }^{6}$ While there are many examples where only one firm has got the leading technology in the market, one can easily find as many cases where there are at least two incumbent firms which have separately developed proprietary technologies. The chemical industry is a rich source of such examples although not the only one. For instance, a quick search on trade press showed that Union Carbide, Himont and Mobil compete with each other in selling polypropylene licenses (Morris, 1989); BP and Du Pont compete in polyethylene process technology (Mullin, 1993); in methyl tert butyl ethers (MTBE), UOP, Mobil-BP, and Phillips Petroleum are amongst the competing licensors (Rotman, 1993a). In cumene, Mobil/Badger are the latest entrants in the licensing market which also includes UOP, ABB Lummus Crest, and Monsanto/Kellog (Rotman, 1993b). ${ }^{7}$ Note that what is critical to the argument is competition in the downstream product market. In our model, only firms with access to the technology can produce. In principle, however, one can think of fringe firms that compete in the product market but do not have proprietary technology to license. These fringe firms can, by reducing the rent dissipation effect, induce licensing. In this paper we do not explore this possibility further and instead focus on competition between technology holders.

${ }^{8}$ In general, the revenue effect may prevail whenever there is more than one incumbent. If $\pi(n)$ represents the profit of the typical firm when there are $n$ firms in the industry, then an incumbent's marginal payoff from
} 
shared with the other incumbent in the market so that the licensor does not fully internalize the rent dissipation effect. If the revenue effect is larger than the rent dissipation effect, then firms compete not only to supply the products but also to supply their technologies. ${ }^{9}$ The existing theoretical literature on licensing cannot explain why large established firms are licensing their technology at the cost of increasing competition for themselves, because it assumes 'unique' technology holder. ${ }^{10}$ With a single technology holder, the rent dissipation effect is typically larger than the revenue effect for firms capable of large-scale production.

The revenue effect also depends on the strength of intellectual property rights and the relative bargaining power of the licensor and licensee. Our results confirm that stronger property rights and greater bargaining power of the licensor lead to more licensing. The degree of product differentiation across technologies has an important influence on the magnitude of the two effects. If the goods are differentiated the licensee will be a much stronger competitor of the technology holder than of the other incumbent(s). This enhances the rent dissipation effect (which is now internalized to a greater extent by the licensor) and reduces the profitability of the licensing strategy. Thus we find that licensing will be more widespread, the lower the degree of product differentiation.

Moreover, one would expect that the rent dissipation effect would depend on the production and commercial capabilities of the licensor: Large, well-established producers have less to gain from licensing and more to lose from competition. Our results confirm that, all else held equal, research labs license more. Interestingly enough, the model also throws up a less straightforward result, namely that the presence of independent labs may induce a producer-innovator to license more as well.

\footnotetext{
licensing (assuming the licensor captures all the surplus) is $2 \pi(n+1)-\pi(n)$. For $n=1$, it is typically assumed that the marginal payoff is negative. Although the latter condition constitutes a valuable benchmark, our results hold true even if an oligopoly with $k>1$ firms maximizes industry profits.

${ }^{9}$ This might explain why in some industries we find that firms are liberal in licensing their technologies and often compete each other in selling licenses, a strategy which would reduce the profitability both for the industry as a whole and for the firms.

${ }^{10}$ Indeed, much of the literature has focused on the optimal licensing behavior of the inventor once it has developed and patented a new technology or production process (see Gallini and Wright, 1990; Kamien and Tauman, 1986). When the innovator is also active in the product market then either only minor innovations are licensed (Gallini, 1984; Katz and Shapiro, 1985; Rockett, 1990a) or licensing is used strategically to enhance demand (Shepard, 1987) or to choose competitors after the patent expires (Rockett, 1990b) or to deter entry (Gallini, 1984). Some of the literature also focuses on how licensing might encourage or refrain firms from investing in R\&D (Katz and Shapiro, 1985; Gallini and Winter, 1985). Although we do not formally model the $R \& D$ stage of the game, we shall comment on this issue in section 6 .
} 
We also use the model to derive conditions for a policy aimed to stimulate licensing to be welfare improving. Licensing is typically welfare improving when we have few patent holders. Instead, when competition in the market for technology is high, we show that, at the equilibrium, one can actually have too much licensing compared to the socially efficient level of licensing.

\section{The model}

Consider a sector where $N$ firms have independently developed and patented proprietary technologies for the production of a good. Such a good can either be perfectly homogeneous across technologies or differentiated. When the good is differentiated, each technology is suited to produce a given variety of it, with each variety being an imperfect substitute of all the others. ${ }^{11}$

Besides the $N$ patent holders we assume that there exist many potential entrants who do not have innovative capabilities but can produce if they receive the rights to use the technology from one of the incumbents. Incumbents can therefore both produce themselves (by using their installed production facilities) and license their technology to potential entrants. When the good is homogeneous across technologies, a licensee is located in the product space at the same distance from all the other producers. The greater the degree of product differentiation, the closer the licensee is in the product space to the licensor, relative to other incumbents.

Let $k_{i}-1$ be the number of licenses sold out by firm $i=1,2, \ldots, N$. Hence, the total number of firms that have the technology and can produce the (differentiated) good is equal to $\sum_{i=1}^{N} k_{i}$. Qualitative results would not change if one assumes the existence of a fringe of firms that can get access to the technology without obtaining a license from one of the technology holders (for instance, through imitation). ${ }^{12}$ For analytical tractability we shall consider $k_{i}$ and $N$ to be continuous variables.

\footnotetext{
"For tractability, we assume symmetry across all varieties. This amounts to assuming that each technology variant is equally differentiated with respect each one of the other variants.

${ }^{12}$ Details are available from the authors upon request.
} 
Technology transfer from the licensor to the licensee involves a fixed cost, $F$, which captures the transaction costs of licensing. We also assume that $\sigma \in[0,1]$ is the share accruing to the licensor of total profits earned by its licensee through the use of the technology. ${ }^{13}$ Both $F$ and $\sigma$ help account for the costs associated with the arms' length contracts, although we do not explicitly model the details of the contractual arrangements. ${ }^{14}$ Note that we do not allow collusion in the product market, even though in principle such collusion can be achieved through suitable licensing contracts. Although such contracts are feasible, they are rare and likely to be prosecuted as anti-competitive.

We analyze the following two-stage game. First, each patent holder decides how many licenses to sell out to potential entrants ("competition in the market for technology") and then, all firms that have got the technology supply the (differentiated) good ("competition in the downstream market"). We proceed by backward induction.

\section{Competition in the downstream market (stage two).}

We assume Cournot competition in the downstream market. ${ }^{15}$ Inverse demand function for each variety $i$ has the following linear schedule ${ }^{16}$ :

$$
p_{i}=1-\sum_{k_{i}} x_{i}-\mu \sum_{N \backslash i} \sum_{k_{j}} x_{j}
$$

for any $i=1,2, \ldots, N$, where $p_{i}$ denotes the price, the first summation is across quantities supplied by firms producing $i$, and the second summation is across all quantities supplied by firms endowed with technology different from $i(N \mid i$ stands for all varieties but $i$ ).

Here, a key parameter is $\mu$, which captures for the degree of product differentiation across varieties. We assume that $\mu \in[0,1]$, with varieties being homogeneous for $\mu=1$ and

\footnotetext{
${ }^{13}$ There are several reasons for the licensor not to be able to extract the full rents generated by its technology: asymmetric information, weak intellectual property regime, bargaining power, uncodifiability of knowledge, etc.

${ }^{14}$ For instance, the licensor might choose a combination of royalties and lump sum payments to maximize profits. Since, in our model there are no production costs, this formulation corresponds to a royalty fee on total sales - a practice that is widespread in licensing contracts (Arora, 1995; Anand and Kanna, 1997). The design of the optimal license contract, for both exclusive and non-exclusive contracts has been studied by Katz and Shapiro (1986), Gallini and Wright (1990) and Arora (1995) among others, and is beyond the scope of this paper.

${ }^{15}$ Some of the results hold under very general functional forms, as noted below.

${ }^{16}$ Notice that this demand structure could be derived from the maximization of a quadratic utility function (see for instance, Singh and Vives, 1984, and Sutton, 1998).
} 
completely differentiated (independent) for $\mu=0$. To keep things as simple as possible, we assume that all technologies allow production at zero marginal cost. Also, notice that we are implicitly imposing that the good is perfectly homogeneous within the group (i.e. all firms using the same technology) and equally differentiated across all groups.

Denote by $\pi^{i}\left(k_{i}, k_{-i}, \mu, N\right)$ the profits accruing to each firm endowed with technology $i$ in the last stage of the game, where $k_{-i}$ stands for the vector $\left\{k_{l}, k_{2}, \ldots, k_{i-1}, k_{i+1}, \ldots k_{N}\right\}$ of firms endowed with technologies different from $i$.

Result 1: Given $k_{i}$ firms producing variety $i=1,2, \ldots, N$, profits of each final producer are:

$$
\pi^{i}\left(k_{i}, k_{-i}, \mu, N\right)=A^{-2} B^{-2}
$$

where $A=\left[1+(1-\mu) k_{i}\right]$ and $B=\left[1+\sum_{N} \frac{\mu k_{j}}{1+(1-\mu) k_{j}}\right]$.

Furthermore, $\pi^{i}$ is increasing and convex in $k_{i}$.

Proof. See the Appendix.

Notice that for $\mu=0$ each firm's profit only depends on the number of firms producing that given variety. Instead, for $\mu=1, \pi^{i}$ depends on the total number of firms active in the market $\sum_{i=1}^{N} k_{i}$.

\section{Competition in the market for technology (stage one).}

Given the results of quantity competition in the last stage of the game one can express each patent holder's profit as a function of the number of firms producing each variety of the good, $k_{i}$ and $k_{-i}$. That is:

$$
V^{i}\left(k_{i}, k_{-i}, \sigma, \mu, N, F\right)=\left[1+\sigma\left(k_{i}-1\right)\right] \pi^{i}\left(k_{i}, k_{-i}, \mu, N\right)-\left(k_{i}-1\right) F .
$$

Each technology holder $i$ chooses $k_{i}$ in order to maximize its total profit given by the expression above. The first order condition is therefore: 


$$
V_{k}^{i}=\sigma \pi^{i}+\left[1+\sigma\left(k_{i}-1\right)\right] \pi_{k}^{i}-F \leq 0 \quad \text { for } k_{i}-1 \geq 0 .
$$

The second order condition is given by ${ }^{17}$ :

$$
V_{k k}^{i}=2 \sigma \pi_{k}^{i}+\left[1+\sigma\left(k_{i}-1\right)\right] \pi_{k k}^{i}
$$

while the stability condition for the equilibrium requires that (see Dixit, 1986) ${ }^{18}$

$$
-V_{k_{i} k_{i}}^{i} \pm \sum_{j \neq i}^{N} V_{k_{i} k_{j}}^{i} \geq 0
$$

From the first order condition (expression (4)), one can identify the two effects due to licensing we have discussed in the introduction. ${ }^{19}$ The first one, $\sigma \pi^{i}$, is positive and corresponds to the revenue effect, which we defined as the increase in profits due to a marginal increase in the number of licensees (and hence in the license fees obtained). The second, $\left[1+\sigma\left(k_{i}-1\right)\right] \pi_{k}^{i}$, is negative and corresponds to the profit dissipation effect due to an increase in the final stage competition (through licensing the patent holder creates more competition which lowers profits). The magnitude of these two effects and the value of $F$ determine whether firms license at equilibrium and if so, how many licenses are sold. Before studying in detail the licensing equilibrium, we want to stress again how important is the presence of competitors in the licensing decision of the innovator. To this end, assume that $N$ $=1$. Then we can state:

Result 2: If $N=1$, no licensing occurs at equilibrium. The presence of competing firms expands the parameters' space under which licensing occurs at equilibrium.

Proof. The first order condition can be rewritten as

$$
V_{k}^{i}(N=1)=\sigma \frac{1}{\left(1+k_{i}\right)^{2}}-\left[1+\sigma\left(k_{i}-1\right)\right] \frac{2}{\left(1+k_{i}\right)^{3}}-F
$$

\footnotetext{
${ }^{17}$ At any interior equilibrium, the second order condition for local maximum is always satisfied. See the Appendix.

18 As we shall discuss later there is only one stable equilibrium with licensing.

${ }^{19} \mathrm{~A}$ third effect is due to the additional transaction costs for each new license agreement.
} 
which is always negative for any $k_{i} \geq 1$. Now, assume $N \geq 2$ and all patent holders but $i$ hold fixed the number of licenses sold out at $k_{j}$. For simplicity assume that $\mu$ tends to 1 . It is easy to check that the first order condition for firm $i$ can be rewritten as

$$
V_{k}^{i}=\frac{1}{\left(1+k_{i}+(N-1) k_{j}\right)^{3}}\left[3 \sigma-2+\sigma\left((N-1) k_{j}-k_{i}\right)\right]-F
$$

which is positive for small values of $F$ and $\sigma$ close to 1 , evaluated at $k_{i}=1$, and $k_{j} \geq 1$.

This result illustrates the key idea behind our framework with more technology holders. While a monopolist innovator would not license out its technology to firms competing in the same market, the simple fact that we move from $N=1$ to $N \geq 2$ gives rise to a strategic effect which can induce firms to license out their technology.

We can now solve for the symmetric equilibrium of the second stage of the game and explore how the optimal number of licenses is affected by the parameters of our model.

Proposition 1: a) A symmetric Nash equilibrium generically exists; b) Both the non-licensing equilibrium (NLE) and the licensing equilibrium (LE) can coexist;

c) There exists at most one stable $L E$.

Proof. See the Appendix.

Since we focus here on symmetric equilibria alone, we can simplify the analysis of existence and stability by defining $\Phi(k, \sigma, \mu, N) \equiv V_{k_{i}}{ }^{i}\left(k_{i}=k, k_{-i}=k, \sigma, \mu, N\right)$, i.e. as the marginal revenue from licensing evaluated at a symmetric licensing level, $k$. Note that the set of symmetric equilibria is given by $\Phi(k)=F$. Notice further that stability requires that $\Phi_{k}(k)<0$.

In Figure 1, the parameters' values chosen are such that we have a unique stable licensing equilibrium (LE). Figure 2 shows a case of multiple equilibria, where the nonlicensing (NLE) and the licensing equilibrium (LE) coexist. It turns out that this is the only case in which we have multiplicity of stable equilibria. In the Appendix we work out necessary conditions for existence of the LE and multiple equilibria. Figure 2 also helps 
underscore the importance of the presence of competitors in shaping the licensing decision of the innovator. For the range of parameter values depicted in figure 2 , no firm would license out its technology if the competitors would not do it, but when all the other firms are licensing the best response is to license as well.

We proceed now by analyzing the symmetric stable equilibrium. Denote by $V_{k}$ the first order condition evaluated at the symmetric equilibrium. One can then show the following:

Proposition 2: In a symmetric stable equilibrium, $k$ is non-decreasing in $\sigma$ and non-increasing in $F$.

Proof. The key to the proof is that in a symmetric stable equilibrium, the direction of change of $k$ depends only on the sign of the cross-partial of the payoff function. One can directly verify that $V_{k \sigma} \geq 0$ and $V_{k F} \leq 0$, thus giving us the required results.

The interpretation in the case of $\sigma$ is straightforward: Proposition 2 implies that any factor that increases the bargaining power of licensors, or decreases the transaction costs involved in licensing will increase licensing. The interpretation with respect to $F$ is more interesting from a policy perspective. Arora and Gambardella (1994), Anand and Khanna (1997) and Merges (1998), have argued that stronger intellectual property rights reduce the transaction costs of technology licensing. If so, then our result finds empirical support in Anand and Khanna (1997). Based on a sample of 1612 licensing agreements, they find that sectors where IPRs are strong are also those with a higher incidence of licensing activity, while sectors with weak IPRs tend to have joint ventures and other such bundled arrangements for transferring technology. Note also that Proposition 2 is completely general and does not rely on the assumption of Cournot competition in the downstream market. Moreover, it applies both to the NLE and LE.

We now examine how the the number of competitors, $N$, and the degree of product differentiation in the market, $\mu$, affect licensing. 
Proposition 3: For $F=0$, in a symmetric stable equilibrium, the number of licenses by each technology holder is non-decreasing in $N$.

Proof. At the symmetric stable equilibrium, the direction of change of $k$ depends only on the sign of the cross-partial of the payoff function. By differentiating $V_{k}$ with respect to $N$, one obtains:

$$
V_{k N}=\sigma \pi_{N}+\left[1+\sigma\left(k_{i}-1\right)\right] \pi_{k N} .
$$

Using $V_{k}=0$ we can rewrite (10) as:

$$
V_{k N}=\sigma\left(\pi_{N}-\pi \frac{\pi_{k N}}{\pi_{k}}\right)+F \frac{\pi_{k N}}{\pi_{k}}
$$

where the expression between parenthesis can be showed to be always positive (see the Appendix). Hence, $V_{k N}>0$ at $F=0$.

From expression (10) one can see that an increase in the number of incumbents involves two forces working in opposite directions. More competition reduces the magnitude of the revenue effect, reducing the payoff from licensing. However, more competition also reduces the size of the profit dissipation effect and hence reduces the opportunity cost of licensing.

At $F=0$ the second force prevails. Under positive transaction costs, the two forces have different magnitudes, and only a weaker version of proposition 3 survives. The intuition is borne out by Figure 3. We have drawn the $\Phi(k, N)$ curve for two different level of $N, N_{l}$ and $N_{2}$, with $N_{2}>N_{1}$. By proposition 2, $\Phi\left(k, N_{2}\right)$ crosses the horizontal axe to the right of $\Phi\left(k, N_{l}\right)$. However, for a set of parameter values, the curves cross in the positive quadrant (at $k>1$ ). This implies that, for large values of $F$, an increase in $N$ could decrease the equilibrium number of licenses. We can partially characterize the situation as follows:

Result 4: There exists an $N^{*}>2$, such that, in a symmetric stable equilibrium with licensing, $k$ is increasing in $N$ for any $N<N^{*}$, and decreasing in $N$ for any $N$ $>N^{*}$. Further, $N^{*}$ is decreasing in $\mu, F$ and $\sigma$. 
Proof. See simulations in the Appendix.

This result implies that even with positive transaction costs, increases in competition in the market for technology initially increase licensing. Only later, as the number of patent holders increases, further increases in competition decrease licensing by reducing the profitability of the product market.

We now state and prove one of the most robust results of the paper which can also be empirically tested most easily. The intuition is quite straightforward. When the good is highly differentiated, each firm has a well-defined market niche. Any entrant the patent holder will license will be a closer competitor to the patent holder itself, and the negative pecuniary externality for other incumbents will be smaller. When the good is homogeneous, the licensor benefits from the fact that the negative effect due to increased competition is spread across all incumbents, while it obtains all (or part of) the profits of the new entrants.

As with the static comparative with respect to $N$, there are two forces at work. On the one hand, less differentiation implies a smaller revenue effect, but on the other hand, it also reduces the profit dissipation effect. It turns out that the second force always prevails. This result is robust and holds also for Bertrand competition with a multinomial logit demand specification (see the Appendix for more details).

Proposition 4: At any LE that involves at least one license per patent holder, $k$ is non-decreasing in $\mu$.

Proof. We prove it by contradiction. First, notice that in a symmetric stable equilibrium, the direction of change of $k$ depends only on the sign of the cross-partial of the payoff function. By differentiating $V_{k}$ with respect to $\mu$, one obtains:

$$
V_{k \mu}=\sigma \pi_{\mu}+\left[1+\sigma\left(k_{i}-1\right)\right] \pi_{k \mu}
$$

where $\pi_{\mu}<0$ and $\pi_{k \mu}>0$ (see the Appendix). Then, suppose that $V_{k \mu}<0$, which implies that $V_{k \mu \sigma}<0$. Take $\sigma=1$. If we prove that $V_{k \mu}$ cannot be negative at $\sigma=1$, then it must be the case that it cannot be negative for any $\sigma$. Indeed, one can show that such that for all 
admissible parameter values, $k \geq 2$ implies $V_{k \mu}<0 .{ }^{20}$ Hence, $V_{k \mu}$ must be positive at any $k \geq 2$.

Patterns of technology licensing in the chemical industry provide empirical support for proposition 4. Elsewhere (see Arora and Fosfuri, 1998) we find that the per-firm number of licenses decreases with the degree of product differentiation in the chemical industry. Homogeneous sectors like air separation, pulp and paper, and petrochemicals are marked by extensive licensing, while we observe only limited licensing by producers in differentiated product groups like pharmaceuticals and organic chemicals.

\section{Welfare}

Does a policy which stimulates licensing always increase welfare? The answer is not always in the affirmative and it turns out that under certain circumstances we might have too much licensing with respect to the socially efficient level.

In computing the socially efficient level of licensing we assume that the market structure is given (i.e. $N$ is exogenous) and that firms compete à la Cournot in the downstream market. Therefore, the social planner can only choose the symmetric number of licenses per-firm, $k$.

Welfare is the sum of consumer surplus ${ }^{21}$ and net industry profits, i.e.

$$
W=N\left\{1 / 2\left(k^{2} x^{2}[1+\mu(N-1)]\right)+\underset{\text { consuner surplus }}{k x^{2}-(k-1) F}\right\}
$$

where $x=[1+(1-\mu) k+\mu N k]^{-1}$.

Result 5: The socially efficient number of licenses per-firm is

$$
k^{s}=\frac{1}{1+(N-1) \mu}\left(\frac{1}{\sqrt[3]{F}}-1\right)
$$

\footnotetext{
${ }^{20}$ Although licensing implies that $k$ should be no less than two, the result reported in proposition 4 holds at any $k>l$ when either $F=0$, or $N<15$, or if product differentiation is low enough. (See the Appendix for details.) ${ }^{21}$ The expression for the consumer surplus can be derived from a quadratic utility function of the form $U\left(X_{1}, \ldots, X_{N}\right)=\sum_{i} X_{i}-0.5 \sum_{i} X_{i}^{2}-\mu \sum_{i} \sum_{j \neq i} X_{i} X_{j}$, where $X_{i}=\sum_{k_{i}} x_{i}$ (see for instance, Sutton,
} 1998), or integrating the inverse demand function at the symmetric $k$ and $x$. 
Proof. Follows directly by maximizing expression (13) with respect to $k$.

Notice that $k s$ is decreasing in $N$ and $\mu$ and tends to infinity as $F$ goes to zero. Furthermore, it does not depend on $\sigma$. The latter is helpful for our main result with respect to welfare.

Proposition 5: There exists an $N^{\circ} \geq 2$ such that for any $N<N^{o}, k^{S}>k^{*}$ and for any $N \geq N^{o}, k^{s} \leq k^{*}$.

Proof. See the Appendix.

The reason why there might be excessive licensing at the equilibrium is because of the transaction costs, which are clear dead-losses associated with licensing. As $N$ becomes larger this inefficiency tends to grow. Indeed, the following corollary helps to highlight this aspect of proposition 5:

Corollary 1: At $F=0$, private licensing is always insufficient, i.e. $k^{*}<k^{S}$.

Proof. Notice that $N^{o}$ tends to infinity as $F$ tends to zero, which implies that for any $N$ $<\infty, k^{*}<k^{S}$.

Finally, we consider possible policy interventions aimed to increase the share of profits accruing to the licensor, $\sigma$. For instance, policies that lower the cost of patent enforcement, or that raise the penalties for patent infringement will increase the share of profits that the licensor can extract. Result 6 shows that a policy aimed to rise $\sigma$ is likely to improve welfare when there are few technology holders, transaction costs are small and products are rather differentiated. Note also that Result 6 provides only a sufficient condition for such policies to be welfare improving, and such policies may be desirable even otherwise. 
Result 6: Any policy that increases $\sigma$ is welfare improving if $N \leq \underline{N}=2+\frac{1-\mu}{\mu \sqrt[3]{F}}$.

Proof. Since $N^{o}$ is decreasing in $\sigma, \underline{N}<N^{o}$, where $\underline{N}=N q_{\sigma=1}$. Hence, by proposition 5 private licensing is insufficient. By proposition $2, k^{*}$ is non-decreasing in $\sigma$, therefore an increase in $\sigma$ enhances welfare.

\section{Small firms and research labs}

In this section we analyze how the equilibrium of the game would be affected by the presence of firms with limited production capability (i.e. small firms and research labs). To this purpose, consider a slightly more general profit function for the innovator:

$$
V^{i}=\left[\lambda+\sigma\left(k_{i}-1\right)\right] \pi^{i}-\left(k_{i}-1\right) F
$$

where $\lambda \geq 0$ captures for the size of the installed production facilities. Large values of $\lambda$ are associated with big corporations, while $\lambda=0$ corresponds to the case of research labs. We can then derive the following result:

Result 7: $k_{i}^{*}$ is decreasing in $\lambda$.

Proof. Consider the first order condition for firm $i: V_{k}^{i}=\left[\lambda+\sigma\left(k_{i}-1\right)\right] \pi_{k}^{i}+\sigma \pi^{i}-F$. Take any pair $(\underline{\lambda}, \bar{\lambda})$ such that $\underline{\lambda}<\bar{\lambda}$. Since $\pi_{k}^{i}<0$, it is easy to see that $V_{k}^{i}=\left[\bar{\lambda}+\sigma\left(k_{i}(\underline{\lambda})-1\right)\right] \pi_{k}^{i}+\sigma \pi^{i}-F<0$, which implies that $k_{i}(\bar{\lambda})<k_{i}(\underline{\lambda})$.

In other words, small firms and research labs tend to license more than big corporations. The intuition behind this result is fairly simple: having little or no production capability means that the extent of the profit dissipation effect is smaller and, hence, licensing is a more appealing strategy.

Perhaps less obvious is how the presence of research labs influences the licensing behavior of firms with installed production facilities. Consider the case of a duopoly where 
instead of having two producers (i.e. two firms with installed production facilities), one of them is replaced by a research lab. Then, we have the following result

Result 8: In a duopoly setting, substituting a producer with a research lab increases the number of licenses sold out by the remaining producer.

Proof. Consider the cross-partial of the profit function in (14) with respect to $k_{i}$ and $k_{j}$, i.e. $V_{k_{i} k_{j}}=\sigma\left[\left(k_{i}-1\right) \pi_{k_{i} k_{j}}+\pi_{k_{j}}\right]+\lambda \pi_{k_{i} k_{j}}$. Now, assume that $V_{k_{i} k_{j}} \leq 0$. Since $\lambda \pi_{k_{i} k_{j}}>0$, this implies that $\left[\left(k_{i}-1\right) \pi_{k_{i} k_{j}}+\pi_{k_{j}}\right]<0$ and therefore that $V_{k_{i} k_{j} \sigma}<0$. Hence, $\left.V_{k_{i} k_{j}}(k)\right|_{\sigma=1} \leq\left. V_{k_{i} k_{j}}(k)\right|_{\sigma<1} \leq 0$. Finally, one can show that there are no combinations of parameters such that at $\sigma=1$ and $k_{i}=k_{j}, V_{k_{i} k_{j}}(k) \leq 0$ at any $k>1$.

What result 8 illustrates is an inducement effect: The presence of a research lab stimulates the licensing activity of the big firm at a level that it wouldn't have reached otherwise. ${ }^{22}$ Elsewhere (see Arora and Fosfuri, 1998) we provide some empirical support to results 7 and 8 . Using data from the chemical industry, we find both that firms without downstream facilities tend to license more and that in product groups where such firms operate more intensively, large chemical producers themselves tend to license more.

\section{Incentives for $R \& D$}

In section 4, we have established sufficient conditions for an increase in the per-firm number of licenses to be socially desirable. Note well that our definition of welfare takes as exogenously given the number of licensors in the economy. But as well understood in the literature on innovations, an increase in the rate of diffusion also implies a smaller incentive to develop the innovation in the first place. This is precisely what occurs in our model where a larger $k$ means lower per-firm profits.

\footnotetext{
${ }^{22}$ Does result 8 fully generalize? One can show that at $F=0, V_{k_{i} k_{j}}>0$ (see the Appendix), which implies that in a model with no transaction costs the presence of research labs always increases the number of licenses sold out by all other producers. For positive values of $F$, result 8 holds unchanged provided that $N$ is small enough.
} 


\section{Proposition 6: With ex-ante symmetric licensors, the possibility of licensing} reduces profits per innovator.

Proof. Licensor's profits in a symmetric equilibrium are: $V\left(k^{*}\right)=\left[1+\sigma\left(k^{*}-1\right)\right]\left[1+(1-\mu) k^{*}+\mu N k^{*}\right]-\left(k^{*}-1\right) F$. Taking the derivative with respect to $k^{*}$ it is easy to show that it is always negative.

Proposition 6 also suggests that patent holders might have incentives to collude in order to reduce or stop licensing and hence increase profits. An example of such a practice is provided by the history of the chemical sector. Before WWII, cartels were widespread. The major technology leaders, which were typically European firms, adopted a strict control over their licensing policies in order to keep market shares, deter entry and sustain prices above competitive levels (see Arora, 1997).

Factors that affect incentives to license therefore have ambiguous effects. For instance, an increase in transaction costs or a decrease in the bargaining power of the licensor (i.e. share of profits extractable from the licensee) might actually increases profits for innovators (and hence, the incentives to undertake R\&D). Using the envelope theorem one can show that $V_{\sigma}^{i}=(k-1) \pi^{i}+\sum_{j \neq i} \frac{d V^{i}}{d k_{j}} \frac{d k_{j}}{d \sigma}$, where the second term is negative and $V_{l \cdot \sigma}^{i}=-(k-1)+\sum_{j \neq i} \frac{d V^{i}}{d k_{j}} \frac{d k_{j}}{d F}$, where the second term is positive. The effect of $\sigma($ or $F)$ on firms' profit is ambiguous since two forces are pushing in opposite directions: on the one hand, a larger $\sigma$ (or a smaller $F$ ) increases licensor's profit; on the other hand, it also stimulates (by proposition 2) the licensing activity of all the other competitors and hence reduces profits.

\section{Conclusion}

There is increasing evidence about the importance of intellectual property rights in many sectors of the economy. Firms in these sectors are looking to profit from the intellectual property not just by embodying it in their own output but also by licensing their intellectual property to others, including potential competitors. Such behavior is difficult to 
understand in the context of models with only a single technology holder, who by definition faces no competition in the product market.

By relaxing the widespread assumption of a 'unique' patent holder, our paper shows that licensing might be the result of firms' strategic behaviors. Indeed, the presence of competition drastically changes the incentives for an incumbent to license its technology to potential entrants. In particular, when there are multiple technology holders, they not only compete in the downstream market but also in the market for technology. Thus, our paper provides an initial framework for analyzing the nature and properties of markets for technology.

Within this framework, we showed that the propensity to license decreases the higher the transaction costs, the lower the bargaining power of the licensor and the lower the protection of intellectual property rights. Also, we found that the average number of licenses sold out by each patent holder is a decreasing function of the degree of product differentiation in the sector. Finally, we showed that small firms and firms without downstream activity tend to license more and that their presence might induce large corporations to license more as well.

Markets for technology imply technology diffusion and increased entry, which improves the static efficiency of markets. However, by inducing entry, markets for technology may reduce the incentives to undertake R\&D. Moreover, if licensing involves transaction costs, our model suggests that the presence of competitors in the market for technology might induce firms to an inefficiently high level of licensing. In general, policies aimed to stimulate licensing are likely to be welfare improving when there are few technology holders and products are differentiated. 


\section{References}

Anand, B. N., and Khanna, T., 1997, "Intellectual property rights and contract structure", WP 97-016, Harvard Business School.

Anderson, S., Palma, A., and Thisse, J., 1992, Discrete Choice Theory of Product Differentiation, Cambridge, Mass., MIT Press.

Arora, A., 1995, "Licensing Tacit Knowledge: Intellectual Property Rights and the Market for Knowhow", Economics of Innovation and New Technology 4, 41-59.

Arora, A., 1997, "Patent, licensing and market structure in the chemical industry", Research Policy 26, 391-403.

Arora, A., and Fosfuri, A., 1998, "Licensing in the chemical industry", paper presented at the conference on "Intellectual Property and Industry Competitive Standards" at Stanford, April 16-17, forthcoming, Stanford Technology Law Review.

Arora, A., and Gambardella, A., 1994, "The changing technology of technological change: General and abstract knowledge and the division of innovative labour", Research Policy, 23, 523-532.

Cohen, W., Nelson, R., and Walsh, J., 1996, "Appropriability Conditions and Why Firms Patent and Why They Do Not in the American Manufacturing Sector", paper presented at the OECD Conference on "New Indicators for the Knowledge Based Economy".

Dixit, A., 1986, "Comparative Statics for Oligopoly," International Economic Review 27, 107-22.

Gallini, N. T., 1984, "Deterrence through Market Sharing: A Strategic Incentive for Licensing", American Economic Review 74, 931-941.

Gallini, N. T., and Winter, R. A., 1985, "Licensing in the theory of innovation", RAND Journal of Economics 16(2), 237-252, Summer.

Gallini, N. T., and Wright, B. D., 1990, "Technology transfer under asymmetric information", RAND Journal of Economics 21(1), 147-160, Spring.

Grindley, P. C., and Teece, D. J., 1997, "Licensing and Cross-Licensing in Semiconductors and Electronics", Californian Management Review.

Kamien, M., and Tauman, Y., 1986, "Fees versus Royalties and the Private Value of a Patent", Quarterly Journal of Economics 101, 471-491.

Katz, M., and Shapiro, C., 1985, "On the Licensing of Innovations", RAND Journal of Economics 16, 504-520.

Katz, M., and Shapiro, C., 1986, "How to License Intangible Property", Quarterly Journal of Economics 101, 567-589.

Merges, R., 1998, "Property Rights, Transactions, And The Value of Intangible Assets", mimeo, Boalt School of Law, University of California, Berkeley.

Morris, G. D. L., 1989, “The PP License Battle”, Chemical Week 144(24), 18, Jun 14.

Mullin, R., 1993, "Process technology: Business holds steady”, Chemical Week 152(1), 46-47, Jan $6 / 13$.

Rockett, K., 1990a, "The quality of licensed technology", International Journal of Industrial Organization 8(4), 559-574.

Rockett, K., 1990b, "Choosing the competition and patent licensing", RAND Journal of Economics 21(1), 161-171.

Rotman, D., 1993a, "Race to license new MTBE and tame routes heats up", Chemical Week 152(1), 48-49, Jan6/13.

Rotman, D., 1993b, "Mobil/Badger to market zeolite-based cumene technology", Chemical Week 152(7), 9, Feb 24.

Shepard, A., 1987, "Licensing to Enhance Demand for New Technology", RAND Journal of Economics, 18, 360-368.

Singh, N., and Vives, X., 1984, "Price and quantity competition in a differentiated duopoly", $R A N D$ Journal of Economics 15(4), 546-555. 
Spalding, B. J., 1986, "Is It Smart to License Out Technology?", Chemical Week 138(15), 30-31, Apr 9.

Spitz, P. H., 1988, Petrochemicals: The Rise of an Industry, John Wiley, New York.

Sutton, J., 1998, Technology and Market Structure: Theory and History, MIT Press.

Teece, D. J., 1988, "Technological Change and the Nature of the Firm", in Dosi, G., et al. (eds.), Technological Change and Economic Theory, Printer Publishers, London. 


\section{Appendix}

\section{A. Proof of result 1}

Take any firm $i$ (either patent holder or licensees) producing variety $i$. By maximizing firm $i$ 's profits with respect to its own quantity we obtain the following first order condition:

$$
1-\sum_{k_{i}} x_{i}-\mu \sum_{N \backslash i} \sum_{k_{j}} x_{j}-x_{i}=0 .
$$

First, impose symmetry across firms using the same technology. Then, by adding and subtracting $\mu \sum_{k_{i}} x_{i}$ we obtain:

from which

$$
1-k_{i} x_{i}-\mu \sum_{N} k_{j} x_{j}-x_{i}+\mu k_{i} x_{i}=0
$$

$$
x_{i}=\frac{1-\mu \sum_{N} k_{j} x_{j}}{1+(1-\mu) k_{j}}
$$

Now, multiply both sides by $\mu k_{i}$ and sum up across all possible varieties to obtain:

$$
\sum_{N} \mu k_{j} x_{j}=\left[1-\sum_{N} \mu k_{j} x_{j}\right] \sum_{N} \frac{\mu k_{j}}{1+(1-\mu) k_{j}}
$$

which after some manipulation can be rewritten as

$$
\sum_{N} \mu k_{j} x_{j}=\frac{1}{1+\frac{1}{\sum_{N} \frac{\mu k_{j}}{1+(1-\mu) k_{j}}}}
$$

Then, substituting (A.5) in (A.3) and simplifying we obtain the equilibrium quantity by each firm (either patent holder or licensee) producing variety $i$ as a function of the numbers of firms active in the production of all varieties $\left(k_{1}, k_{2}, \ldots, k_{N}\right)$ :

$$
x_{i}=\left[1+(1-\mu) k_{i}\right]^{-1}\left[1+\sum_{N} \frac{\mu k_{j}}{1+(1-\mu) k_{j}}\right]^{-1} \text {. }
$$

Replacing expression (A.6) in (1) we can compute the equilibrium price for each variety, and then profits as reported in result 1. Furthermore, with some algebra one can derive $\pi_{k}^{i}=-2 A^{-4} B^{-3}[A B(1-\mu)+\mu]<0$ and $\pi_{k k}^{i}=6 A^{-6} B^{-4}[A B(1-\mu)+\mu]^{2}>0$.

\section{B. Second order condition is satisfied at any stable LE.}

We want to show that $V_{k k}^{i}<0$. The second order condition is $V_{k k}^{i}=2 \sigma \pi_{k}^{i}+\left[1+\sigma\left(k_{i}-1\right)\right] \pi_{k k}^{i}$. Using the first order condition, one can write $V_{k k}^{i}=2 \sigma \pi_{k}^{i}+\frac{F-\sigma \pi^{i}}{\pi_{k}^{i}} \pi_{k k}^{i}=2 \sigma \pi_{k}^{i}+\frac{F-\sigma \pi^{i}}{\pi_{k}^{i}}\left(\pi_{k}^{i}\right)^{2} \frac{3}{2 \pi^{i}}$. Simplifying further we obtain $V_{k k}^{i}=\pi_{k}^{i}\left[\frac{\sigma}{2}+\frac{3 F}{2 \pi^{i}}\right]<0$. 


\section{Proof of result 3.}

Recall that $\Phi(k)$ is the marginal revenue from licensing evaluated at the symmetric licensing configuration. We can rewrite $\Phi(k)=g(k) f(k)$, where $g(k)$ is quadratic in $k$, with $g_{k k}<0$, and

$f(k)=\frac{[1+k(1+u(N-1))]^{-3}}{1+(1-\mu) k}>0$.

Consider any value of $\mu<1$. (At $\mu=1$ and $F=0$, a symmetric Nash equilibrium might not exist). Let $k_{I}$ and $k_{2}$ be the two roots of $g(k)=0$, with $k_{2}>k_{l}$. Notice that since $g(k)<0$ at any $k>k_{2}$ then at any $k>k_{2}, \Phi(k)$ must be negative $(f(k)$ is always positive). Now, let $\Phi(1)-F<0$. Hence, a symmetric Nash equilibrium exists where no firms license. On the contrary, let $\Phi(1)-F>0$. Since $\Phi(k)<0$ for any $k>k_{2}$ then it must be that $k_{2}$ $>1$. Since $\Phi(k)$ is continuous for $k>0$, then at least one stable LE must exist.

To show uniqueness of the stable LE we take some intermediate steps. First, notice that $\Phi_{k}=0$ is cubic in $k$. Hence, $\Phi(k)$ has three inflection points. Second, we show that one inflection point is on the right of $k_{2}$. To this purpose notice that $\Phi(k)$ tends to zero as $k$ approaches infinity. Moreover, $\Phi(k)<0$ at any $k>k_{2}$, which implies that there must exists a $k_{3}>k_{2}$ such that $\Phi_{k}\left(k_{3}\right)=0$. Third, we show that $\Phi(k)$ has only one inflection point for $\Phi(k)>0$. (See Figure 4a and 4b.) Suppose that $\Phi_{k}(1)>0$, then since $\Phi_{k}\left(k_{2}\right)<0$, we only have an odd number of inflection points in the interval $\left[1, k_{2}\right]$. Since the maximum number of inflection points for $k<k_{2}$ is two, then there must be only one inflection point in the interval $\left[1, k_{2}\right]$. By a similar argument one can exclude multiplicity of inflection points in the interval $\left[1, k_{2}\right]$ for $\Phi(k)$, when $\Phi_{k}(1)<0$ and $\Phi(1)<0$. Finally, consider the case where $\Phi_{k}(\mathrm{l})<0$ and $\Phi(1)>0$. One can show that, under these two conditions, $\Phi_{k}(k)<0$ for any $k<$ $k_{2}$. Indeed, $\Phi_{k}(1)<0$ and $\Phi(1)>0$ imply that $g_{k}(1)<0$ which implies that $g_{k}<0$ at all $k>1$. But $g_{k}<0$ implies $\Phi_{k}(k)<0$ for any $k$ belonging to the inverval [ $\left.1, k_{2}\right]$. Only one inflection point in the interval $\left[1, k_{2}\right]$ means that $\Phi(k)=F$ can at most have two roots. It is then easy to see that only the larger root is stable.

Finally, a necessary and sufficient condition for having multiple equilibria is that the smallest root of $\Phi(k)=F$ is greater than 1. (See Figure 2.) We show necessary conditions for the existence of multiple equilibria in the next section.

\section{Necessary conditions for the existence of the symmetric stable LE and for the existence of multiple equilibria.}

We first derive the set of conditions which insure the existence of a symmetric stable $L E$ at $F=0$. Such conditions are only necessary at $F>0$ (while they are also sufficient at $F=0$ ).

Let $k_{l}$ and $k_{2}$ be the two roots of $\Phi(k)=0$, with $k_{2}>k_{1}$. For the existence of a symmetric stable LE we want $k_{2}$ be a real number greater than 1 (greater than two if we are only interested in integer values of $k$ ). It turns out this is the case when the following two conditions are satisfied: $\beta^{2}-4 \alpha \gamma \geq 0$ and $\alpha+\beta+\gamma<0$, where $\beta=\sigma(1-\mu)+[1+\mu(N-1)[2(1-\sigma)(1-\mu)-\sigma], \gamma=2-3 \sigma$ and $\alpha=\sigma(1-\mu)[1+\mu(N-1)]$. It is easy to check that both conditions are satisfied for large values of $\mu, \sigma$ and $N$.

To derive necessary conditions for the existence of multiple equilibria (sufficient at $F=0$ ) one has to force $k_{I}$ to be greater than 1 . This is the case when the following conditions are simultaneously satisfied: $\beta^{2}-4 \alpha \gamma \geq 0$, $2 \alpha+\beta<0$ and $\alpha+\beta+\gamma>0$. It is easy to check that all conditions hold for small values of $\sigma$, intermediate values of $N$ and large values of $\mu$ (for instance, $\sigma=0.25, N=5, \mu=0.98$ ).

\section{E. Proof of proposition 2}

With some algebra one can show that: $\pi_{N}=-2 \mu k A^{-3} B^{-3}$ and $\pi_{k N}=2 \mu k A^{-5} B^{-4}[2(1-\mu) A B+3 \mu]$. It follows that $\pi_{N}-\pi \frac{\pi_{k N}}{\pi_{k}}=\frac{\mu^{2} k A^{-3} B^{-3}}{(1-\mu) A B+\mu}$, which is always non-negative. 


\section{F. Proof of result 4}

First, notice that at $N=1, V_{k N}>0$. Second, we prove that $V_{k N}>0$ at $N=2$. Indeed, $\left.V_{k N}\right|_{N=2, \sigma=1}=2 \mu k \widetilde{C}^{-3}[-\widetilde{A} \widetilde{C}+2 \widetilde{C} k(1-\mu)+3 \mu k]$ where $\widetilde{A}=[1+(1-\mu) k]$ and $\widetilde{C}=[1+(1+\mu) k]$. Notice also that if $V_{k N}$ is not negative at $\sigma=1$, then it is not negative at any $\sigma$. Simplifying further we obtain that $\operatorname{sign}\left\{\left.V_{k N}\right|_{N=2, \sigma=1}\right\}=\operatorname{sign}\left\{k^{2}-1+\mu k-\mu^{2} k^{2}\right.$, which is always positive. Hence, $\left.V_{k N}\right|_{N=2}>0$. Now, to show that $V_{k N}>0$ for $N<N^{*}$ and $V_{k N}<0$ for $N>N^{*}$ we use simulations (Mathematica's files are available from the authors upon request). In the figures $5 \mathrm{a}, 5 \mathrm{~b}$ and $5 \mathrm{c}$ we plot the equilibrium value of $k$ as a function of $N$, holding constant all other parameters $(\sigma, \mu, F)$, but one. $k^{*}(N)$ is obtained by solving $\Phi(k, \bar{\sigma}, \bar{\mu}, N)=\bar{F}$. In each figure the value of $N^{*}$ corresponds of the inflection point of $k^{*}(N)$. Notice that the curves joining the inflection points show the response of $N^{*}$ to $\sigma, \mu$, and $F$ respectively in figure 5 a-c.

\section{G. Additional results related to proposition 3}

G.1. $\quad V_{k \mu}>0$ at any $k>1$ and $F=0$.

By differentiating $V_{k}$ with respect to $\mu$, one obtains:

$$
V_{k \mu}=\sigma \pi_{\mu}+\left[1+\sigma\left(k_{i}-1\right)\right] \pi_{k \mu} .
$$

Using $V_{k}=0$ we can rewrite (G.1) as:

$$
V_{k \mu}=\sigma\left(\pi_{\mu}-\pi \frac{\pi_{k \mu}}{\pi_{k}}\right)
$$

With some additional algebra one can show that $\pi_{\mu}=-2 A^{-3} B^{-3} k(N-1)$ and $\pi_{k \mu}>0$. Simplifying further one obtains that $V_{k \mu}=\sigma\left(\pi_{\mu}-\pi \frac{\pi_{k \mu}}{\pi_{k}}\right)=\frac{\sigma A^{-3} B^{-3} u k(N-1)(B+1)}{A B(1-\mu)+\mu}>0$.

G.2. $\quad V_{k \mu}>0$ at any $k>1$ and $\mu=1$.

Some tedious algebra suffices to show that

$$
\left.V_{k \mu}\right|_{\mu=1}=\frac{2 k(N-1)[(4+k N)(1-\sigma)+\sigma(4 k-1+(k-1) k N)]}{(1+k N)^{4}}>0 \text {. }
$$

G.3. $\quad V_{k \mu}>0$ at any $k>1$ and $N<15$.

Notice that $V_{k \mu \sigma}<0$. Take $\sigma=1$. If we prove that $V_{k \mu}$ cannot be negative at $\sigma=1$, then it must be the case that it cannot be negative for any $\sigma$. Solve $\left.V_{k \mu}\right|_{\sigma=1}=0$ with respect to $N$. Only the largest root, $N^{\wedge}(k, \mu)$ is of interest to us. $V_{k \mu}$ is negative at any $N>N^{\wedge}$. Such a root is increasing in $k$. Take $k=1$. Then, one can show that the lower bound of $N^{\wedge}$ is at $\mu=2(2-\sqrt{3})$ and it is equal to 14.92 .

\section{H. Proof of proposition 5}

Take the first order condition evaluated at the symmetric $k_{i}=k_{j}=k^{S}$, i.e. $\left.V_{k_{i}}\right|_{k_{i}=k_{j}=k^{s}}$. Then, solve for the value of $N$, such that $\left.V_{k_{i}}\right|_{k_{i}=k_{j}=k} s=0$. One can show that 
$N^{\circ}(\sigma, \mu, F)=\frac{\left(\frac{1-\sqrt[3]{F}}{u}\right)\left[2 \sigma \mu+(1-\mu)\left(1+\frac{\sigma}{\sqrt[3]{F}}\right)\right]}{\sigma-2(1-\mu)(1-\sigma)-\sqrt[3]{F}[1+2 \mu(1-\sigma)]}+\frac{\mu-1}{\mu}$. It is easy to see that for any $N<N^{o}$ $\left.V_{k_{i}}\right|_{k_{i}=k_{j}=k^{*}}<0$ which implies that $k^{*}<k^{S}$. Also notice that $N^{o}$ is decreasing in $\sigma$. Hence $N^{o}$ reaches a lower bound at $\sigma=1$. Evaluating $N^{o}$ at $\sigma=1$, one obtains $\underline{N}=\left.N^{0}\right|_{\sigma=1}=2+\frac{1-\mu}{\mu \sqrt[3]{F}} \geq 2$.

I. $\quad V_{k_{i} k_{j}}>0$ at $\boldsymbol{F}=0$.

Write $V_{k_{i} k_{j}}=\sigma \pi_{k_{j}}+\left[1+\sigma\left(k_{i}-1\right)\right] \pi_{k_{i} k_{j}}$. Using the first order condition one obtains

$V_{k_{i} k_{j}}=\sigma\left(\frac{\pi_{k_{j}} \pi_{k_{i}}-\pi \pi_{k_{i} k_{j}}}{\pi_{k_{i}}}\right)$, where $\pi_{k_{j}}=\frac{-2 A^{-2} B^{-3}}{\left[1+(1-\mu) k_{j}\right]^{2}}$ and

$\pi_{k_{i} k_{j}}=\frac{2 A^{-4} B^{-4} \mu}{\left[1+(1-\mu) k_{j}\right]^{2}}[2 A B(1-\mu)+3 \mu]$. Some additional algebra shows that

$V_{k_{i} k_{j}}=-\frac{2 \sigma A^{-6} B^{-6} \mu}{\pi_{k_{i}}\left[1+(1-\mu) k_{j}\right]^{2}}>0$.

\section{J. BERTRAND COMPETITION WITH MULTINOMIAL LOGIT DEMANDS}

In this section, we move from quantity competition to a more realist framework where firms set prices.

Notation and assumptions are as in section 3 . Since competition is based on prices, we need to differentiate firms also when they use the same technology. Therefore, we denote by $\rho_{2}$ the degree of differentiation within the 'group' (where 'group' stands for all firms using the same technology). Instead, the parameter $\rho_{1}$ captures for the degree of product differentiation across groups as discussed above. Notice that with this notation a larger $\rho$ means more differentiation. We assume that $\rho_{1}>\rho_{2}$, which amounts to saying that firms using the same technology are closer to each other than to firms using different technologies. For simplicity, assume that total demand is normalized to one and marginal production costs are equal to zero for all firms.

We use the following notation. $S_{i}$ is the share of total demand corresponding to group $i, S_{i \mid m}$ is firm $m$ 's share of group $i$ 's demand. Assuming a logistic distribution for demand, one can show that (see Anderson et al., 1992)

$$
S_{i}=\frac{\left[\sum_{h=1}^{k_{i}} \exp \left(\frac{-p_{i h}}{\rho_{2}}\right)\right]^{\rho_{2} / \rho_{1}}}{\sum_{j=1}^{N}\left[\sum_{h=1}^{k_{j}} \exp \left(\frac{-p_{j h}}{\rho_{2}}\right)\right]^{\rho_{2} / \rho_{1}}} \quad \text { and } \quad S_{i \mid m}=\frac{\exp \left[\frac{-p_{i m}}{\rho_{2}}\right]}{\sum_{h=1}^{k_{i}} \exp \left[\frac{-p_{i h}}{\rho_{2}}\right]} \text {. }
$$

Hence, market share of firm $m$ belonging to group $i$ is simply $S_{i m}=S_{i \mid m} \times S_{i}$ and profits are

$\pi_{i m}=p_{i m} \times S_{i m}$.

We can then solve for the first stage of the game. First order condition ${ }^{23}$ for firm $m$ is:

\footnotetext{
${ }^{23}$ We assume that both second order condition for a local maximum and stability condition for the equilibrium are satisfied. It is easy to check that the second order condition is always satisfied for the simple case where all firms are equally differentiated both within and across groups. In general, stability condition is satisfied for $N$ small.
} 


$$
\frac{\partial \pi_{i m}}{\partial p_{i m}}=S_{i m}+p_{i m}\left(S_{i} \frac{\partial S_{m \mid i}}{\partial p_{i m}}+S_{m \mid i} \frac{\partial S_{i}}{\partial p_{i m}}\right)
$$

Letting (J.1) be equal to zero and simplifying, we get

$$
p_{i m}=\frac{\rho_{1} \rho_{2}}{\rho_{1}\left(1-S_{m \mid i}\right)+\rho_{2}\left(S_{m \mid i}-S_{i}\right)} .
$$

By imposing symmetry within the group (i.e. $p_{i m}=p_{i}$ and $S_{m \mid i}=\frac{1}{k_{i}}$ ) one obtains

$$
p_{i}=\frac{\rho_{2} k_{i}}{\left(k_{i}-1\right)+\theta\left(1-S_{i}\right)}
$$

where $\theta=\frac{\rho_{2}}{\rho_{1}}<1$. By substituting (J.3) in the profit expression we have

$$
\pi_{i m}=\pi_{i}=\frac{p_{i} S_{i}}{k_{i}}=\frac{\rho_{2} S_{i}}{\left(k_{i}-1\right)+\theta\left(1-S_{i}\right)}, \quad \forall m
$$

We now derive a series of results for the case in which $p_{j}=\bar{p}, k_{j}=\bar{k}, S_{j}=\bar{S}, j \neq i$.

Result J.1: In a symmetric equilibrium in prices, an increase in the number of licenses within group $i$, increases group $i$ 's price more than other groups' prices.

Proof. Define $\mathrm{X}=\frac{p_{i}-p_{j}}{\rho_{1}}$. Then using (J.3) and the adding up condition, $S_{i}+\sum_{j} S_{j}=1$, one can write $\frac{\partial X}{\partial k_{i}}\left(1+\frac{k_{i}}{p_{i}} \frac{\theta^{2}}{D^{2}}\right)=-\frac{\theta}{D^{2}}\left[(1-\theta)+S_{i} \theta\left(1-S_{i} \theta\right)\right]<0$, where $D=\left(k_{i}-1\right)+\theta\left(1-S_{i}\right)$.

Result J.2: An increase in the number of licenses within group $i$, increases group $i$ 's market share, less than proportionately.

Proof. $\frac{\partial S_{i}}{\partial k_{i}} \frac{k_{i}}{S_{i}}=\left(\frac{\theta}{k_{i}}-\frac{\partial X}{\partial k_{i}}\right)(N-1) S_{i} k_{i}$, which is positive by result J.1 above. Recall that we are evaluating all expressions at a symmetric outcome, so that $S_{i}=\frac{1}{N} \forall i$. This implies that $\frac{\partial S_{i}}{\partial k_{i}} \frac{k_{i}}{S_{i}}=\left(\theta-k_{i} \frac{\partial X}{\partial k_{i}}\right) \frac{(N-1)}{N}$. Using result J.1, one can show by induction that $-k_{i} \frac{\partial X}{\partial k_{i}}<\frac{N}{(N-1)}-\theta$, so that $\frac{\partial S_{i}}{\partial k_{i}} \frac{k_{i}}{S_{i}}<1$. Notice that this implies $-k_{i} \frac{\partial X}{\partial k_{i}}<\frac{N}{(N-1)}$.

Result J.3: $\frac{\partial \pi_{i}}{\partial k_{i}}<0$ in a neighborhood of the symmetric equilibrium. 
Proof. $\frac{\partial \pi_{i}}{\partial k_{i}}=\frac{\rho_{2}}{D^{2}}\left[\frac{\partial S_{i}}{\partial k_{i}} \frac{k_{i}}{S_{i}}-1-(1-\theta)\right]$ and it is negative by result J.2. This is a common result in almost all models of oligopolistic competition for which an increase in the number of firms reduces the per-firm profit.

Notice that when $\theta$ increases the degree of product differentiation within the group and across the groups become similar. For $\rho_{2}$ held constant, this means that the differentiation across groups falls, groups compete more closely and profits decrease. On the other hand, when groups are less differentiated a decrease in profits due to an increase in competition, i.e. a larger $k_{i}$, is shared across all groups.

Result J.4: Holding $\rho_{2}$ constant, $\frac{\partial \pi_{i}}{\partial \theta}<0$ and $\frac{\partial^{2} \pi_{i}}{\partial k_{i} \partial \theta}>0$.

Proof. In a symmetric equilibrium, each group's share is unchanged. Therefore, $\frac{\partial \pi}{\partial \theta}=-\frac{\pi(1-S)}{D}<0$. Then, $\frac{\partial^{2} \pi}{\partial \theta \partial k}=-\frac{\pi_{k}(1-S)}{D}-\frac{\pi}{D}\left(\frac{\partial S}{\partial k}\right)-\frac{(1-S)}{D^{2}}\left(1-\theta \frac{\partial S}{\partial k}\right)$. Since $\frac{\partial S_{i}}{\partial k_{i}}<\frac{S}{k_{i}}=\frac{1}{N k_{i}}<1$, all three terms on the right hand side are positive.

Result J.5: At any symmetric licensing equilibrium, $V_{k \theta}^{i}>0$.

Proof. $V_{k \theta}^{i}=\frac{1-S}{D}[\sigma \pi(k-1)-F]+[1+\sigma(k-1)] \frac{\pi}{D} \frac{\partial S}{\partial k}\left(1-\frac{\theta}{D}\right)$. At $V_{k}^{i}=0, \sigma \pi(k-1)-F>0$ for $k \geq 1$ and $\theta>D$.

Proposition J.1: In a symmetric equilibrium, the per-group number of firm, $k$, is decreasing in the degree of product differentiation across groups, holding constant the degree of within group differentiation.

Proposition $\mathrm{J} .1$ follows because the sign of the effect of an increase in $\theta$ depends only on the sign of $\mathrm{V}_{\mathrm{k} \theta}$. This proposition is analogous to the proposition derived for the differentiated Cournot model in the text.

Result J.6: $V_{k \rho_{2}}^{i}>0$.

Proof. $V_{k \rho_{2}}=\frac{V_{k \theta}}{\rho_{1}}+\frac{1}{\rho_{1}}\left(1+\sigma(k-1) \pi_{k}+\sigma \pi_{k}\right)=\frac{V_{k \theta}}{\rho_{1}}+\frac{F}{\rho_{2}}>0$.

Proposition J.2: For any given level of product differentiation across group, an increase of the degree of product differentiation within the group increases the per-group number of firm, $k$.

An increment in the degree of product differentiation within the group makes the market more profitable. Each licensee competes less fiercely with other firms belonging to the same group, thus increasing the attractiveness of licensing. Notice that, unlike the Cournot model, it might well be that a 'unique' patent holder would like to license out its technology to competing firms. Indeed, when $\rho_{2}$ is large enough industry profits might be maximized by an oligopoly (even if $N=I$ ). However, the presence of competing technologies still has an effect on firms' licensing behavior, which is to increase the number of licenses, $k$. We did not prove formally this result, but one can argue that the case of $N=l$ corresponds to a situation where firms are completely 
differentiated, that by proposition J.2 means less licensing at equilibrium. Hence, when we move to $N>1$ we should expect more licensing at equilibrium. 


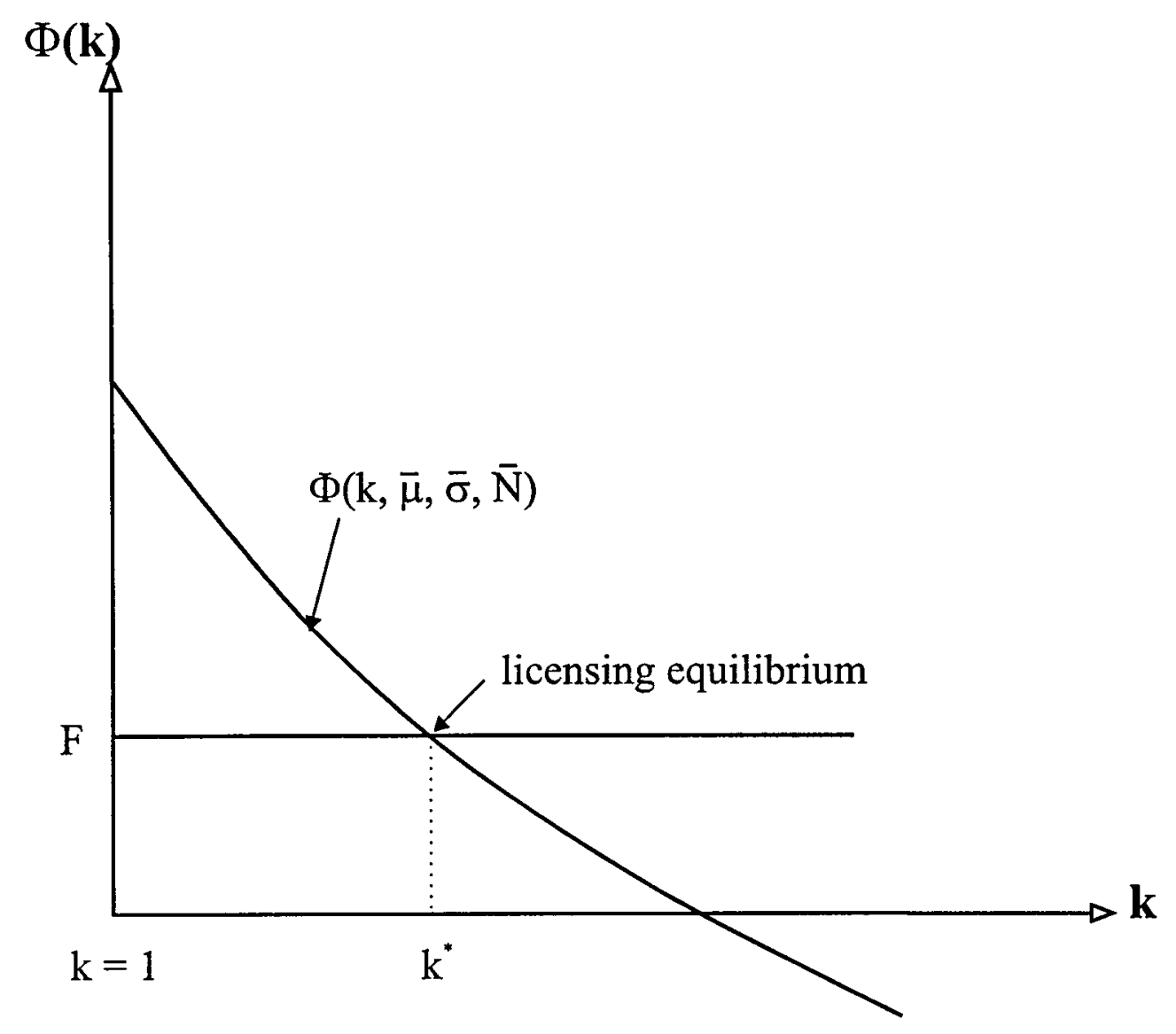

Figure 1: A unique symmetric stable licensing equilibrium 


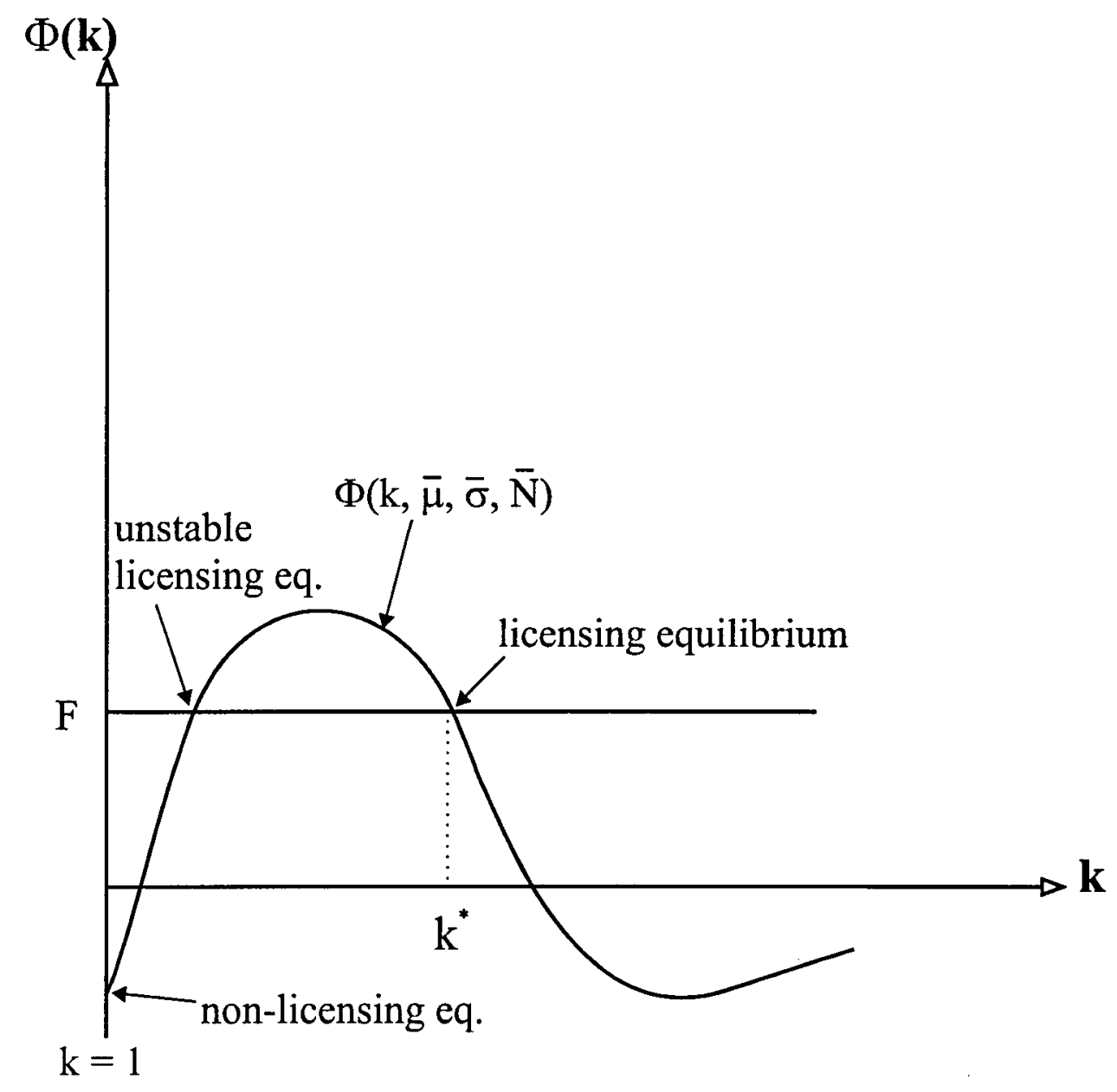

Figure 2: Multiple equilibria 


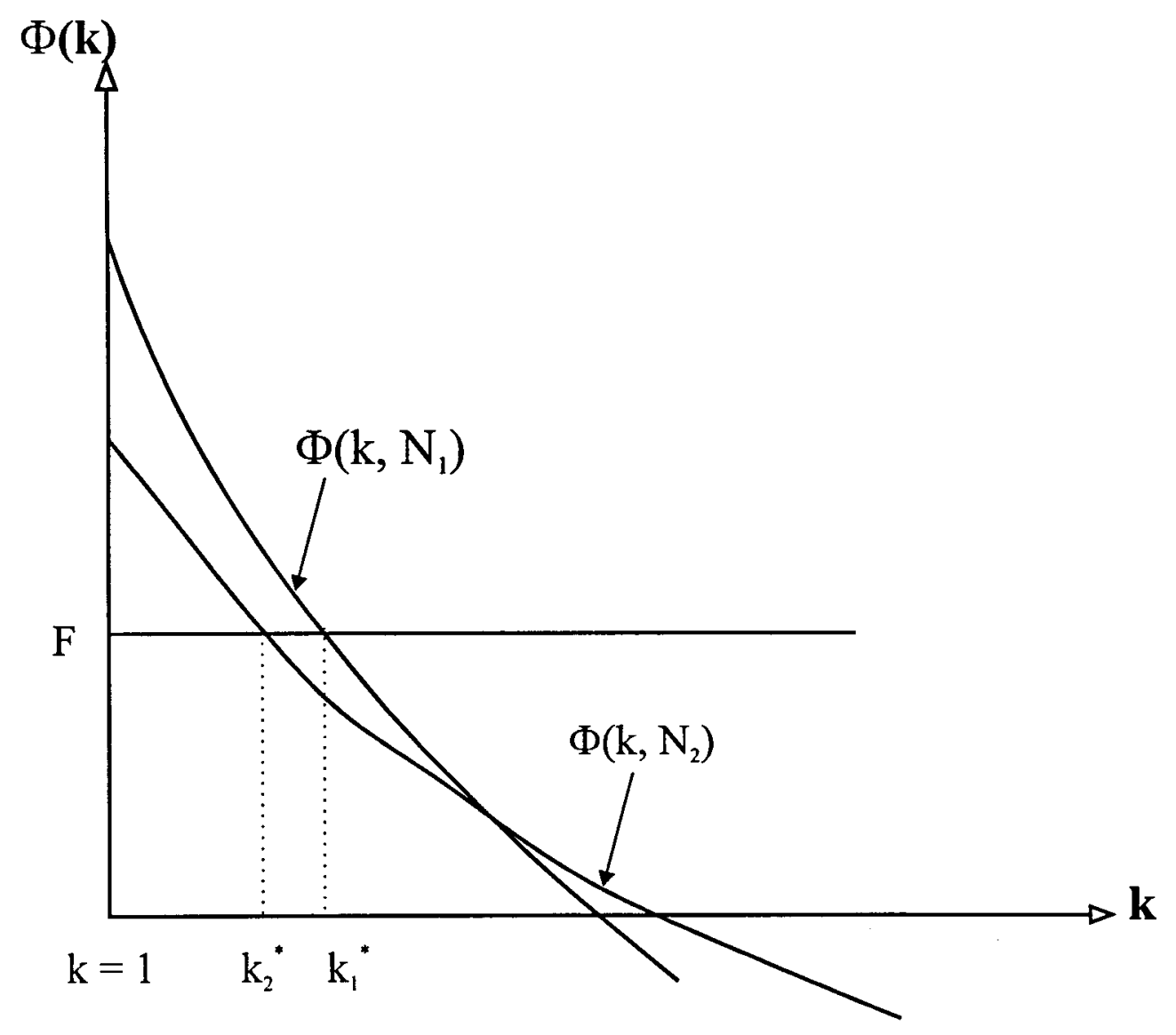

Figure 3: $k$ is decreasing in $N\left(N_{2}>N_{1}\right.$ and $\left.k^{*}\left(N_{2}\right)<k^{*}\left(N_{l}\right)\right)$ 


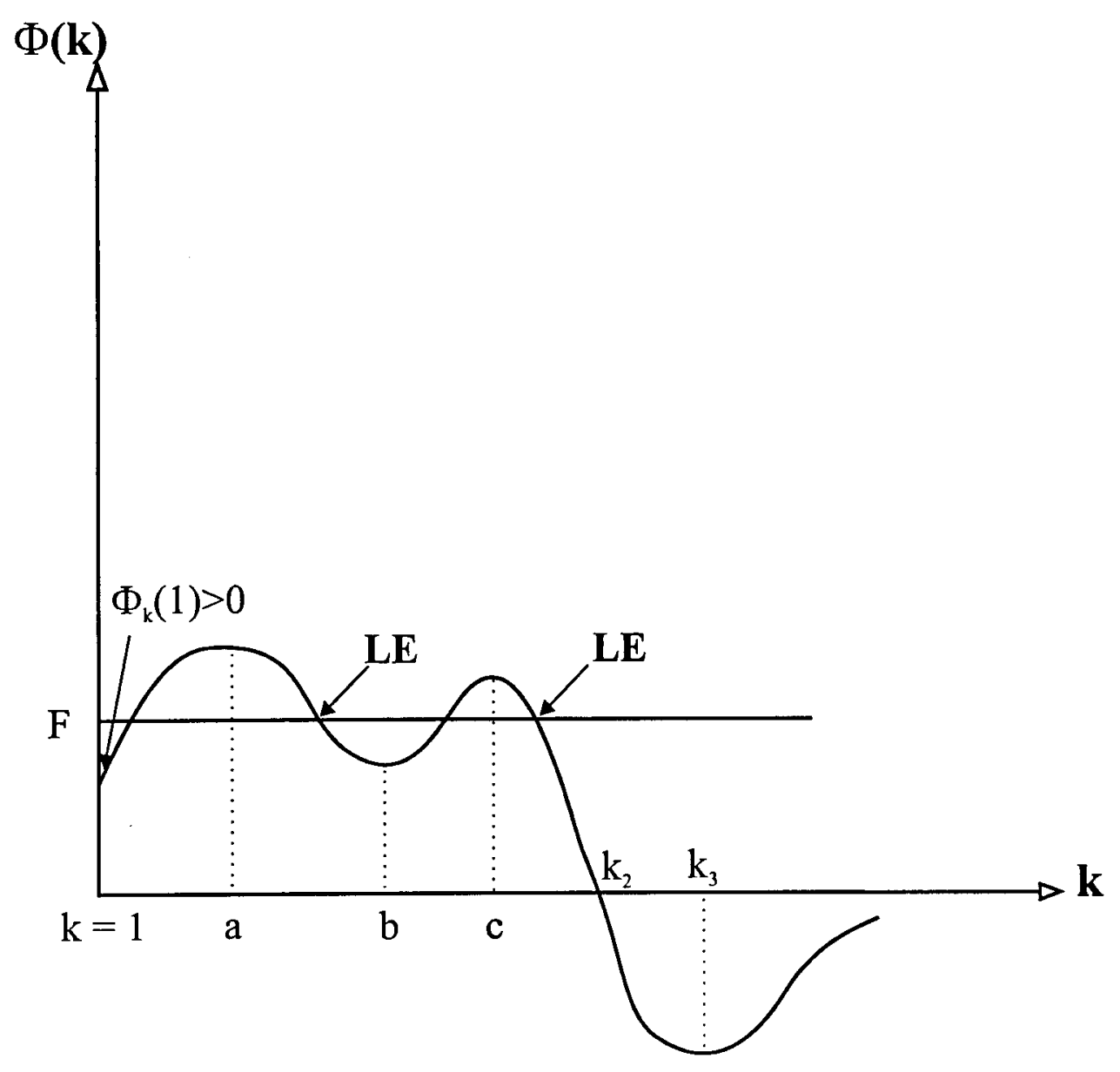

Figure 4a: Not possible, $\Phi(k)$ has at most 3 inflection points 


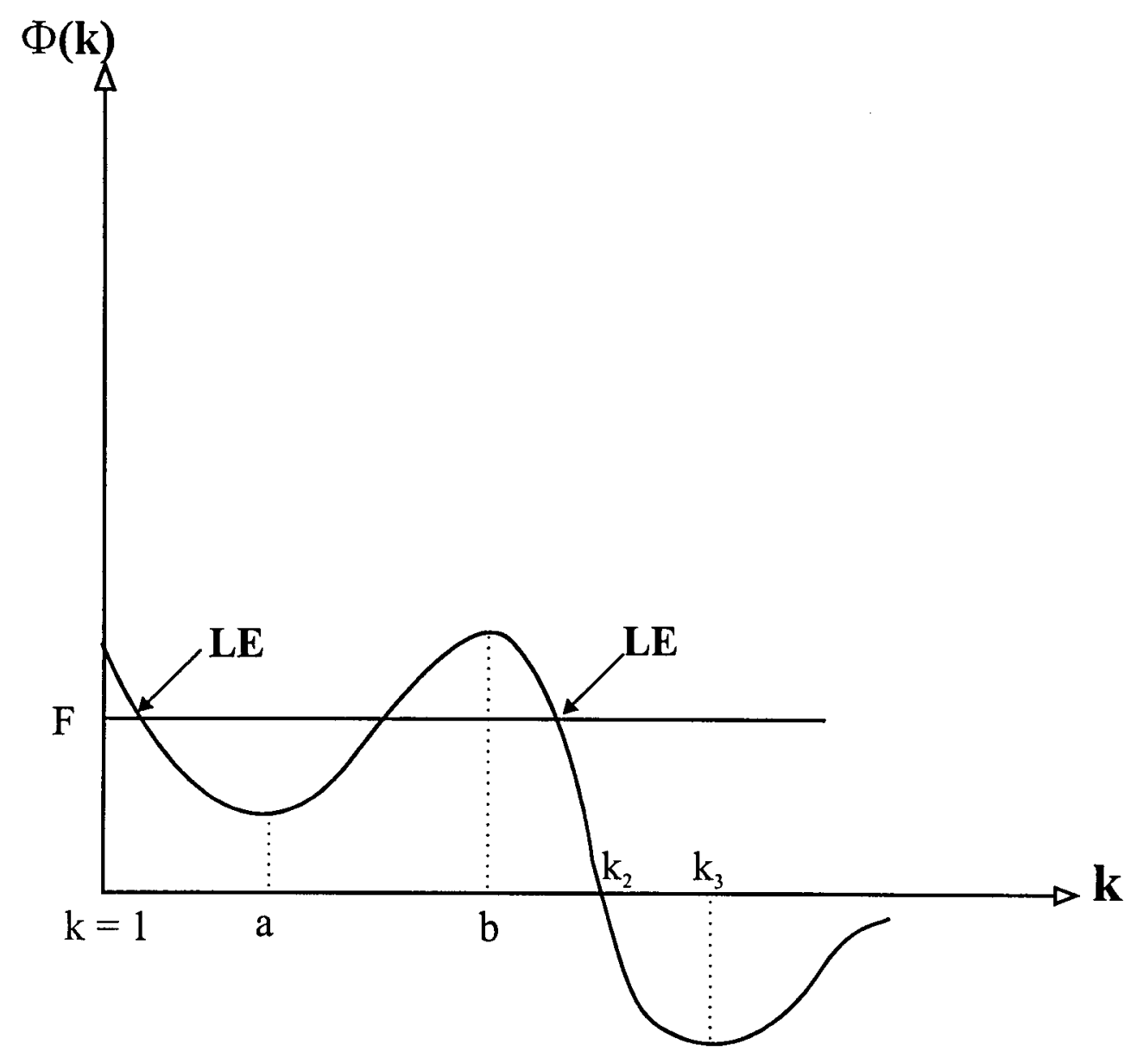

Figure 4b: Not possible, $\Phi_{k}(1)<0$ and $\Phi(1)-F>0$ implies $\Phi_{k}<0$ for any $k<k_{2}$ 


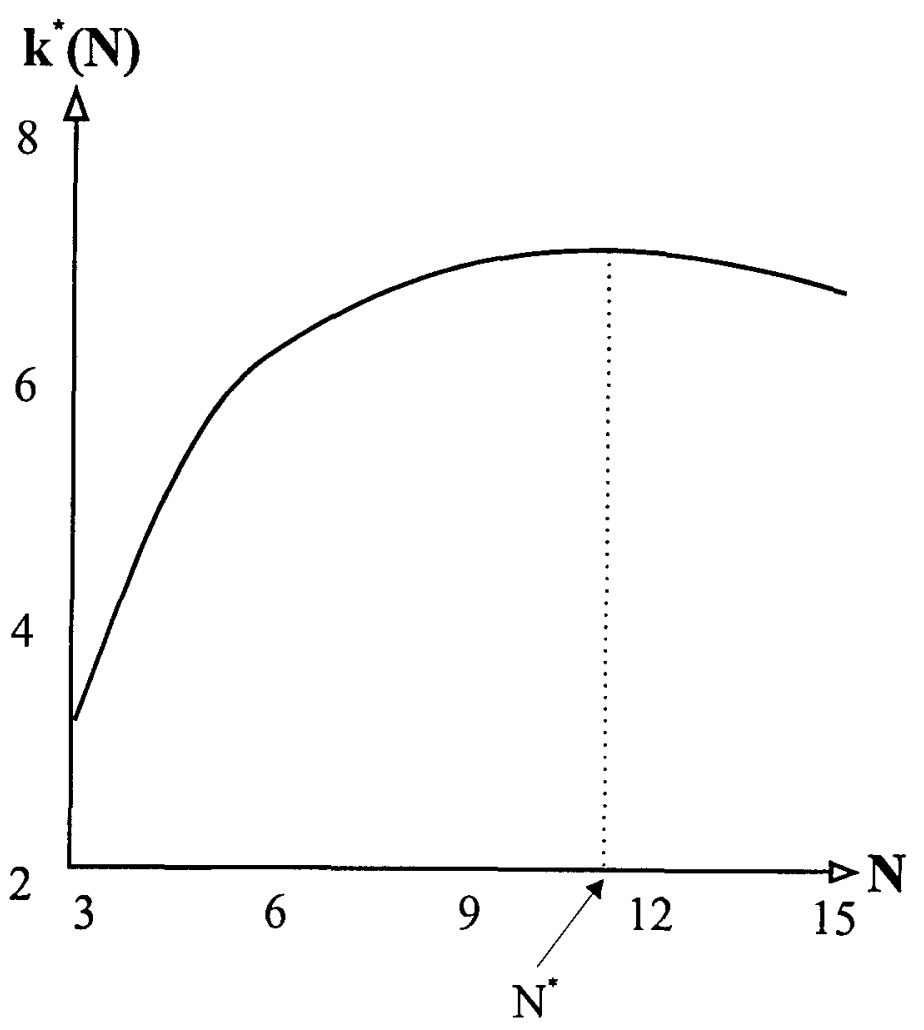

Figure 5: $V_{k N}>0$ if $N>11, V_{k N}<0$ if $N>11$ $(F=0.00001, \mu=0.9, \sigma=0.8)$ 


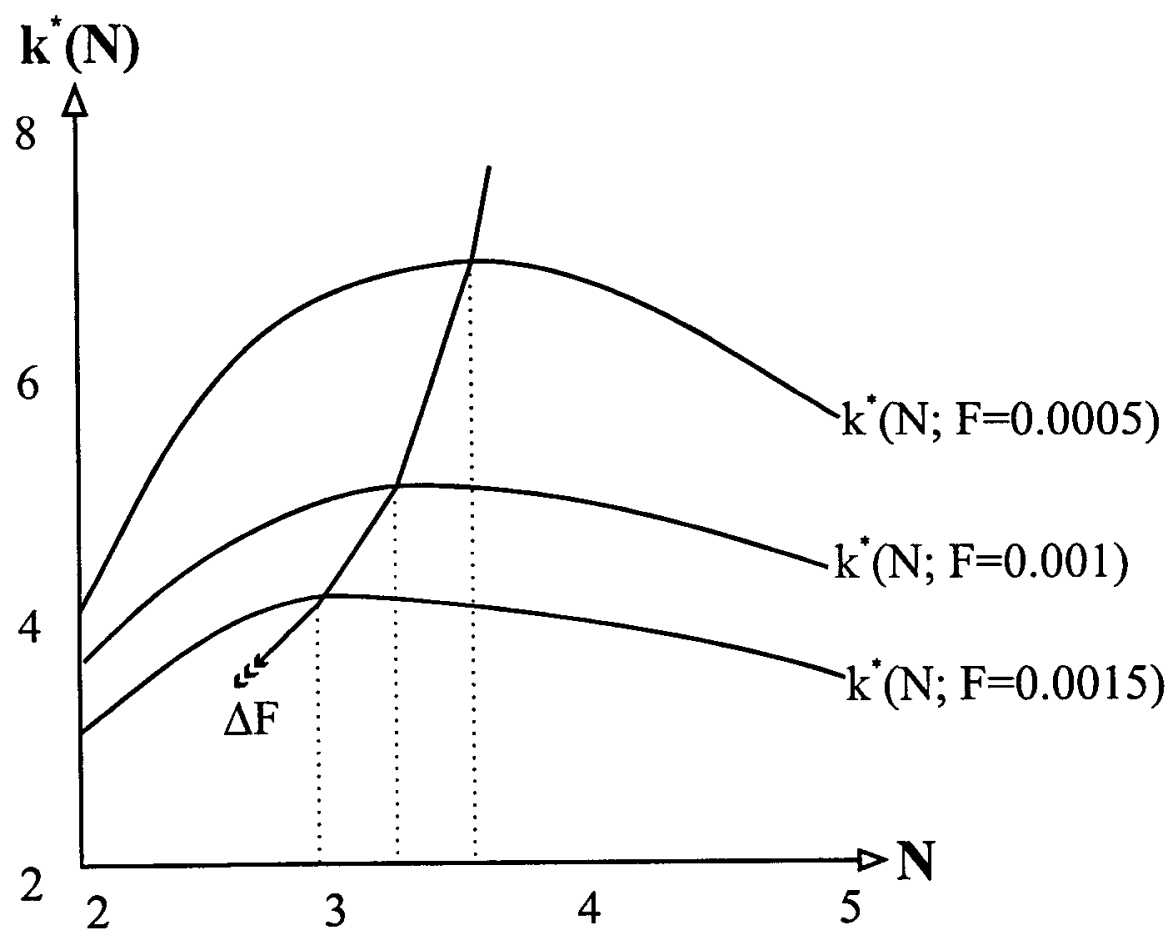

Figure 5a: $N^{*}$ is decreasing in $F(\sigma=1, \mu=0.98)$ 


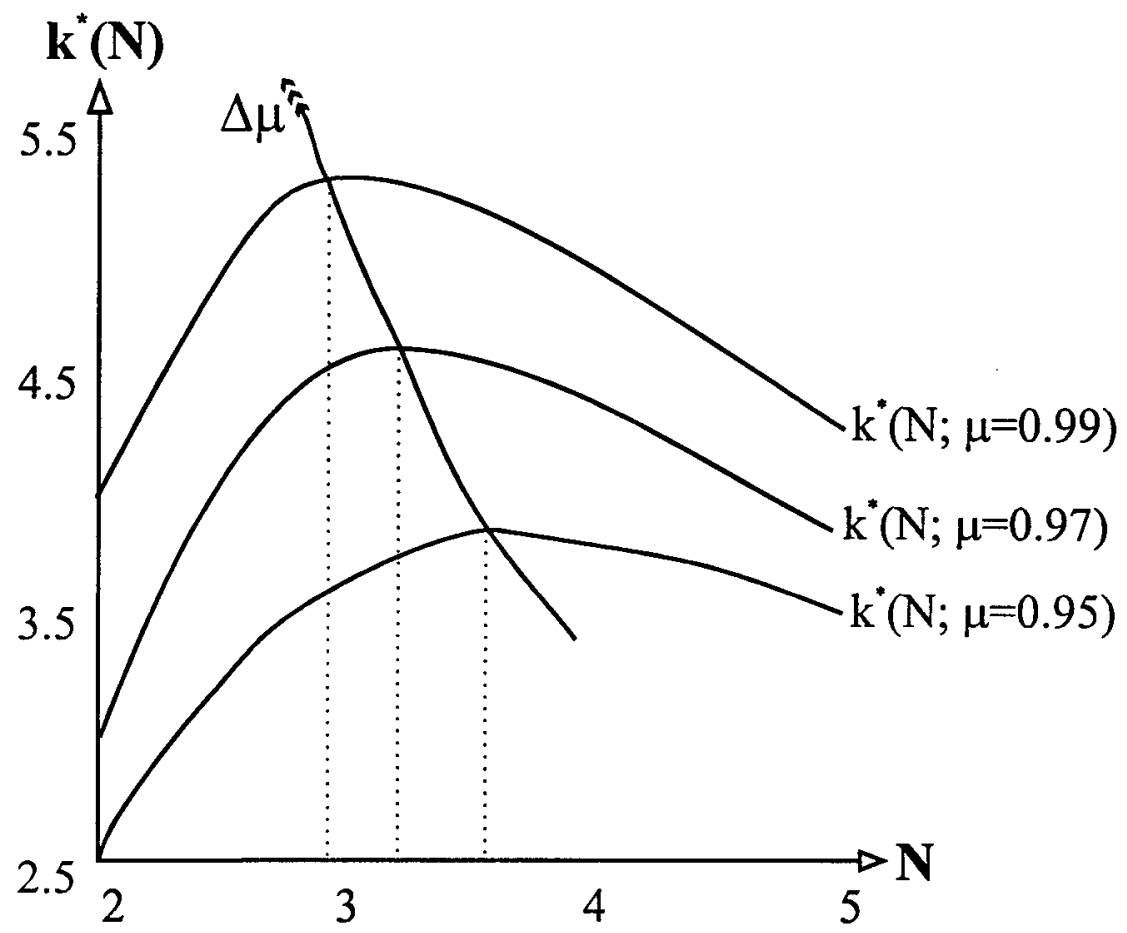

Figure $5 b$ : $N^{*}$ is decreasing in $\mu(\sigma=1, \mathrm{~F}=0.001)$ 


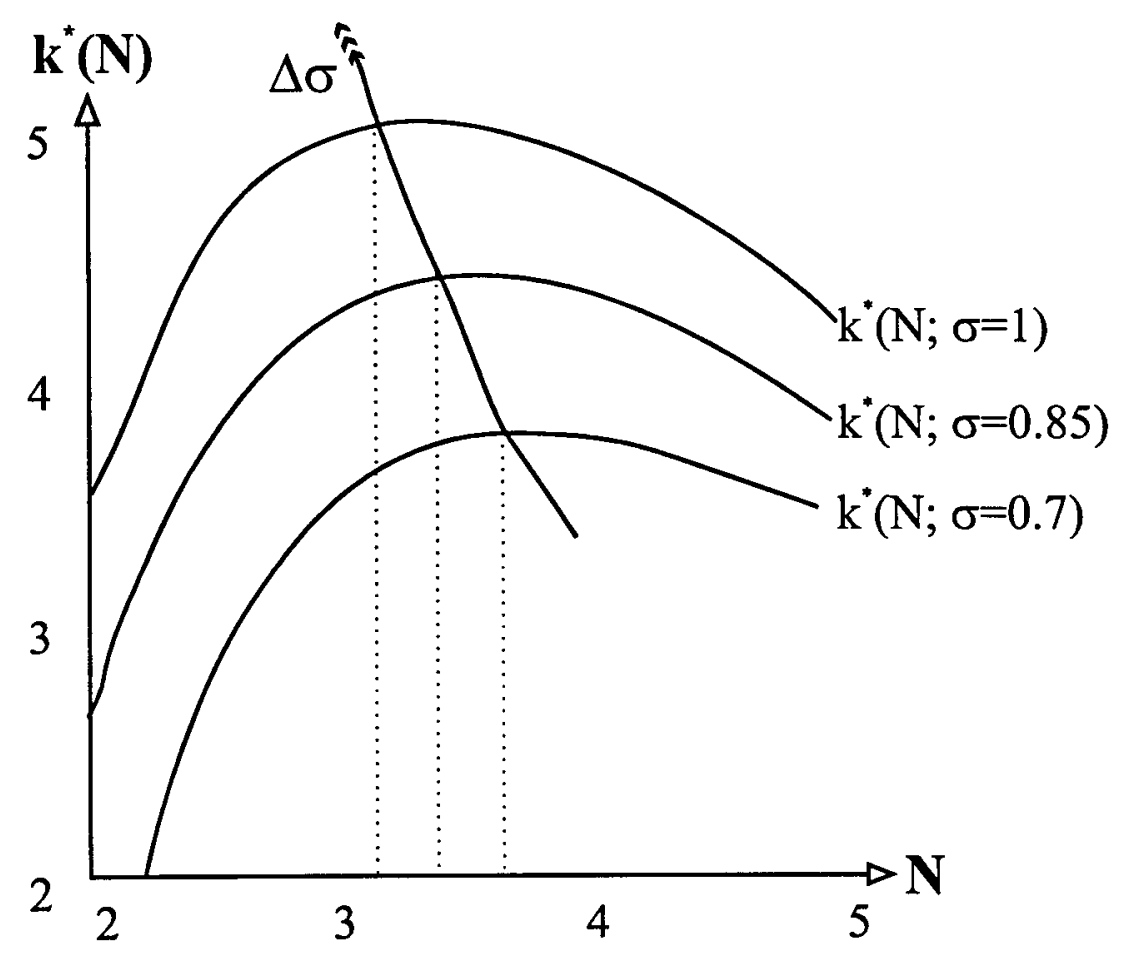

Figure $5 c: N^{*}$ is decreasing in $\sigma(\mu=0.98, \mathrm{~F}=0.001)$ 